\title{
Bioética e Laicidade: reconstruindo pontes entre ciências e humanidades
}

\section{Bioethics and secularism: rebuilding bridges between sciences and humanities}

\author{
Marcia Mocellin Raymundo \\ Hospital de Clínicas de Porto Alegre, Porto Alegre, Rio Grande do Sul, Brasil. \\ marciamocellin@gmail.com
}

\author{
Daniel Gutiérrez-Martínez \\ El Colegio Mexiquense A. C., Ciudad de México, DF, México. \\ dgutierrezcolmex@yahoo.fr
}

Resumo: Em seu livro, Bioética: ponte para o futuro, Van Rensselaer Potter enfatizou a necessidade de uma nova disciplina que estabelecesse uma ponte entre as ciências e as humanidades, a qual chamou de bioética. Contudo, apesar do rápido desenvolvimento da bioética como disciplina (ou interdisciplina), atualmente ainda se percebe uma bioética bastante influenciada por um conteúdo biomédico, e até mesmo medicalizada em certa medida, levantando dúvidas sobre a sua configuração humanista. Entende-se que esta não é uma prática condizente com a proposta original de Potter, pois, como elo entre as ciências e as humanidades, a bioética não deveria assumir posições setoriais, ideologias, dogmas ou doutrinas, mas definitivamente abarcar a pluralidade e a diversidade em seu mais amplo sentido. Sendo assim, a laicidade - enquanto uma proposta de convivência entre todos os membros da sociedade, não importando origem étnica, religião, crenças, não crenças, opção sexual entre outras liberdades de consciência -, pode auxiliar no redimensionamento desta ponte que ainda hoje se encontra por (re)construir. Portanto, este artigo propõe uma reflexão sobre as vicissitudes da bioética, enquanto disciplina ponte entre as ciências e as humanidades, e os aportes que a laicidade, entendida como ferramenta de convivência pode proporcionar à experiência real e cotidiana a este objetivo da bioética.

Palavras-chave: Laicidade. Bioética. Diversidade. Humanidades.

Abstract: In Van Rensselaer Potter's book, "Bioethics: bridge to the future", he
emphasized the need for a new discipline that would establish a bridge between the
sciences and the humanities, which he called bioethics. However, despite the rapid 
development of bioethics as a discipline (or interdiscipline), it can still be seen that bioethics is greatly influenced by biomedical content, and is even medicalized to a certain extent, thus raising doubts about its humanist configuration. It can be understood that this is not a practice in line with Potter's original proposal, considering that, as a link between the sciences and the humanities, bioethics should not take up sectorial positions, ideologies, dogmas or doctrines, but should definitively embrace plurality and diversity in their broadest sense. Thus, secularism - as a proposal for all members of society to live together regardless of their ethnic origin, religion, beliefs, non-beliefs and sexual orientation, among other freedoms of conscience - may assist in revising the dimensions of this bridge, which today is under re(construction). Therefore, this paper proposes a reflection on the vicissitudes of bioethics, as a bridging discipline between the sciences and the humanities, and the contribution that secularism, as a tool for living together, may provide for this objective of bioethics, in the light of real day-to-day experience.

Keywords: Secularism. Bioethics. Diversity. Humanities..

No prefácio de seu lendário livro, intitulado Bioética: ponte para o futuro (1), Van Rensselaer Potter afirma que o seu propósito é contribuir para o futuro da espécie humana, promovendo a formação de uma nova disciplina: a Bioética. Se existem duas culturas que parecem incapazes de dialogar uma com a outra - as ciências e as humanidades - e se essa ausência de diálogo é parte da razão que torna o futuro duvidoso, talvez, então, seja possível construir uma ponte para o futuro. Demonstrando clareza frente ao histórico momento no qual se encontrava, o autor propôs a construção da disciplina Bioética como a ponte entre essas duas culturas. Ao longo do capítulo denominado Bioética, a ciência da sobrevivência, Potter enfatiza que é necessária uma nova disciplina que permita o diálogo entre os diferentes modelos de estilo de vida existentes e que proponha políticas públicas que possam estabelecer a ponte para o futuro. Ou seja, uma comunicação estreita e indelével entre ciência e humanidades, e que esta comunicação não seja negativamente afetada com os aportes das novas tecnologias. E ainda, acrescenta que esta nova disciplina requer uma intercomunicação entre a biologia básica, as ciências sociais e as humanidades.

Contrastando com o preconizado no período no qual o livro foi publicado - marcado pela crescente especialização dos saberes e o consequente isolamento das áreas -, percebe-se nas proposições de Potter uma nítida preocupação em promover a união entre os saberes. Impossível ao leitor não perceber a ênfase dada pelo autor ao 
caráter interdisciplinar necessário à bioética já no início do livro. Mantendo a postura vanguardista desta proposição, Potter reflete sobre pontos de vista historicamente polarizados, a saber: mecanismo versus vitalismo ou reducionismo versus holismo. Curiosamente, os dois conjuntos de oposições se contrapõem - daí o vanguardismo de sua proposta -, com a idéia central de mais que gerar oposições, gerar convergências, não somente entre disciplinas aparentemente diferenciadas, como também entre enfoques no seio das mesmas disciplinas.

O aporte essencial de Potter à proposta da bioética foi deixar claro que não existe possibilidade de uma investigação no mundo biológico sem vínculo com o mundo das relações humanas e vice-versa. Percebe-se claramente como, desde 1971, se esboça o pensamento precursor de Potter acerca da necessidade interdisciplinar para compreender o mundo em que se vive, seja qual for o âmbito da disciplina de referência. Não é por acaso que a referência como pioneiro da bioética se atribui a Potter, ainda que a palavra já houvesse sido citada anteriormente por Fritz Jahr em 1917 (2).

Enquanto o primeiro advoga por uma maneira de encontrar uma ética da vida através do convívio de diferentes disciplinas, o segundo marca a necessidade imperativa de responsabilizar-se eticamente com a vida do mundo que o rodeia. No presente, nos remetemos predominantemente na própria bioética de maneira mais acentuada à conscientização da responsabilidade que temos como espécie humana ao nosso entorno, olvidando-nos das bases que sustentam a disciplina bioética, a saber, o vínculo entre as chamadas ciências e humanidades. Vale lembrar que William Dilthey já mencionava anteriormente para o âmbito das ciências sociais a necessidade de gerar uma ponte entre as ciências do espírito e as ciências históricas (3).

Passados quase quarenta anos da publicação de Bioética: ponte para o futuro alcançamos o futuro e percebemos que a bioética atual talvez não tenha seguido exatamente os rumos propostos por seu idealizador, pois embora atue como importante espaço de reflexão por ocasião de conflitos surgidos em sua maioria nas áreas das ciências da vida e da saúde, a bioética parece ter sido construída sob maior influência destas áreas do que daquelas ditas humanistas. Contudo, como bem enfatiza Juliana GonzálezValenzuela, pela sua própria natureza, pela sua própria história e por sua problemática, na bioética confluem diversas disciplinas (científicas e humanísticas) e ela abarca distintos campos do conhecimento. Segundo a autora, o enfoque filosófico se conjuga com o da medicina, da biologia, do direito, da psicologia, da antropologia, da sociologia, entre outras. E não se trata de uma mera soma ou justaposição de disciplinas, mas de uma efetiva interdisciplina na qual se interpenetram e interatuam as diversas perspectivas e 
metodologias disciplinares (4).

Em que pese todo o esforço de alguns especialistas em assegurar o caráter amplo e abrangente da bioética, atualmente esta se restringe principalmente às questões biomédicas. E, além disso, esta tendência ao protagonismo biomédico na disciplina bioética leva também a que os enfoques e reflexões se restrinjam majoritariamente aos aspectos nosocomiais quando são abordados casos que implicam aspectos mais além dos biomédicos. Como exemplo, podemos citar a visão restrita na abordagem de casos relacionados a pessoas intersex, quando os aspectos biomédicos são privilegiados e os demais aspectos - sobretudo os sociais - são tratados como menos importantes (aspectos identitários, percepções sociais, valores culturais particulares). Fato este também percebido quando as discussões nos Comitês de Bioética enfatizam mais os riscos que uma técnica médica específica possa causar ao paciente do que na pergunta sobre se seria imperativo definir um sexo que corresponda a uma percepção de acordo com o binômio homem/ mulher do ser humano de uma sociedade específica. A este enfoque restritivo chamamos de medicalização da bioética, ou seja, o exercício de uma reflexão baseada muito mais em aspectos técnicos e biomédicos sobre os sintomas relativos ao corpo humano, ou, a uma concepção específica e particular da saúde, que em aspectos que incluem também outras áreas do conhecimento que integram a interdisciplina bioética.

O anterior leva evidentemente a conflitos entre uma perspectiva biomédica ortodoxa (predominante) e outra integral e panorâmica que incluiria reflexões humanistas no momento de decidir sobre as alternativas indicadas para cada caso. Curiosamente seguimos sem construir a verdadeira ponte entre ciências e humanidades. E, pelo contrário, definindo a vida de nosso entorno a partir de conflitos interpretativos do ser humano particularizados em cada campo dos saberes. Contudo, uma ressalva deve ser feita ao termo humanidades, posto que neste contexto não se refira exclusivamente ao ser humano.

Conforme aponta Paulina Rivero Weber, é questionável falar de humanismo no âmbito filosófico atual, pois, por um lado, se trata de um conceito utilizado em tantos e tão diferentes sentidos que dificilmente ainda diz algo, e, por outro, parece que atrás deste termo pode se esconder o tão temido antropocentrismo, ou seja, uma visão que em lugar de basear sua ética no valor da totalidade do planeta ou até mesmo do cosmos, apela unicamente ao ser humano (5). Neste contexto, a visão humanista de Potter abarca justamente seu sentido mais abrangente, incluindo a relação de seres humanos com seu meio ambiente, como podemos verificar desde o prefácio do livro em pauta, onde o autor refere que os valores éticos não podem ser separados de fatos biológicos. E não se trata 
somente de uma proposição sem repercussões, mas, do núcleo central sobre o qual se cimenta a bioética. Os valores éticos são precisamente os pontos básicos comuns (pontos de encontro) sobre os quais as sociedades - que por definição são diversas e relacionais - podem entender-se e conviver.

O conceito de sociedade envolve inegavelmente a interação entre duas ou mais pessoas; sem esta interação não pode existir grupo ou sociedade alguma. Não existe indivíduo sem sociedade, porém pode haver sociedade sem indivíduos. O anterior confirma que a noção de indivíduo é mais uma construção produto da modernidade do que um descritor da essência dos seres humanos. A definição de ser humano se cimenta em razão da relação deste com seu entorno, com os outros. Por isto é sumamente importante que a epistemologia da bioética se fundamente sobre o resultado das relações entre pessoas e a diversidade inerente a cada um.

A vida não se pode dar sem a relação com o outro, portanto, uma ética de vida deve se fundamentar mais na relação entre as pessoas do que na sacralização do indivíduo. Daí resulta, inclusive, que as decisões pessoais não são puramente individuais, pelo fato de que fazem definitivamente referência aos valores e princípios culturais, quer dizer, coletivos e históricos. Ou seja, ainda que existam decisões individuais, pessoais, autônomas, estas sempre estão referidas a um contexto de dois indivíduos ou mais (grupo).

Por sua vez, Potter afirmou a necessidade de várias éticas, ou seja, uma ética da terra (ecosofia), uma ética da vida selvagem (ecologia), uma ética de populações (demografia), uma ética do consumo (capitalismo), uma ética urbana (socio-espacial), também uma ética internacional (direitos humanos) e assim por diante. Segundo Potter, todas estas éticas se constituem a partir de valores e determinantes biológicos que são os elementos básicos que envolvem a bio-ética (1). Inclusive se poderia dizer que, na atualidade, se discute a cerca de uma ecosofia humanista como uma proposta para sintetizar todo este conjunto de éticas, cuja ideia seria a de conceber o ser humano como um elemento a mais, que conforma a complexidade do planeta e não como o elemento central ou essencial. Sem dúvida o anterior constitui os elementos do debate que nos legou Potter, ao ponto que depois de quarenta anos do surgimento da bioética estas discussões seguem presentes na produção acadêmica e leiga sem que tenhamos constituído até o momento - há que insistir a este respeito - uma ponte clara, concreta e consensual entre ciências e humanidades.

Um exemplo que ilustra de maneira representativa o exposto acima é quando alguns autores buscam distinguir a bioética como uma ética aplicada em comparação com 
outras éticas que poderíamos chamar de geral $(6,7)$, resultando na sempiterna discussão se a ética aplicada trata-se de uma nova disciplina ou de uma nova maneira de articular teoria moral e prática. Javier Sádaba (8) afirma que não existe uma ética geral e outra distinta, assim como não existe uma ética masculina e uma feminina, ou uma ética oriental e outra ocidental. A este respeito podemos afirmar que somente se trataria - se seguimos este debate infrutífero - de níveis de concreção, posto que não existe ética aplicada que não seja precedida de uma ética geral, pois a conformação da ética inegavelmente se compõem de valores e de determinantes biológicos próprios a cada comunidade humana. Em outras palavras não existe técnicas que precedam à ética, ou, por exemplo, não se pode desenvolver um medicamento sem que se preceda uma valor-ação de uma doença prévia acordada comumente em grupo (ética). Estes debates nada mais são que um sintoma discursivo da medicalização da bioética, onde o que importa são os fatos e não tudo aquilo que precede a estes fatos, a saber, o acordo de valorações coletivas (encontros de pontos em comum). O anterior quiçá nos levaria a propor níveis de implicação da ética tanto no âmbito prospectivo ${ }^{1}$ (nível epistemológico; como gerar conhecimento) como no âmbito relacional (metodológico; como aplicar o conhecimento).

Portanto, o desafio da bioética parece não estar na discussão se existem diferentes éticas de acordo com Potter ou se se trata de éticas aplicadas ou gerais (6,7 e 8) mas, de seguir buscando concretizar o ponto de partida desde o início da bioética, a saber, as pontes entre valores e fatos biológicos. Provavelmente estas discussões obscureceram as reflexões em torno das pontes entre ciências e humanidades, não somente no seio da própria bioética (valores e fatos biológicos), mas também ao seu entorno interdisciplinário. Desta maneira a bioética em lugar de consolidar-se como uma disciplina ponte entre diferentes saberes, se transfigura em um espaço de interface que, algumas vezes, se vê apropriado por diferentes campos, os quais adquirem uma roupagem de acordo com seus propositores ou à bioética da moda, fragmentando os pressupostos básicos da bioética e gerando utilitarismos disciplinários; a ponto de existir uma bioética com ênfase normativa, relacionada sobretudo à área do direito, outras de cunho mais filosófico, vinculadas sobretudo a teorias de uma visão da bioética, e outras ainda com ênfase na aplicação da bioética na prática e atendimento em saúde, por exemplo. E, até mesmo uma bioética de cunho religioso, quando vinculada a denominações religiosas especificas. Neste caso, corre-se o risco, como acima mencionado, de que a bioética se transfigure em uma disciplina utilitária, que vise somente justificar quem a apregoa, levando a interpretações e aplicações tendenciosas dela mesma, de acordo com sua vertente de origem. Sendo

1. A prospecção aqui se refere a tomar em conta os resultados das interações que se dão entre os grupos entre si e com seu entorno. 
assim, mais que beneficiar a interface característica da bioética que permite o diálogo entre diferentes saberes, podemos nos encontrar circunscritos concomitantemente em um conjunto de interpretações unifacetadas, muitas vezes divulgadas como verdades absolutas ou saberes definitivos, terminando por distanciar-se dos fundamentos sobre os quais se conformou a aurora da bioética. Um exemplo a esse respeito se dá quando especialistas em bioética predeterminam suas teorias bioéticas (éticas de vida) com base em uma interpretação culturalmente particular do que significa concepção e/ou status moral do ser humano, terminando por propor morais de vida (regras e normas de comportamento de vida) correspondentes a grupos particulares. Neste ponto nuclear encontramos as mais álgidas tensões entre a consideração dos particularismos, dos individualismos e dos universalismos, sendo esta tensão precisamente produto do pressuposto de que os primeiros são possíveis de ser considerados compartilhados entre todos (universalismo). As controvérsias a cerca do aborto nas políticas públicas ou das pesquisas com células tronco são um exemplo. Sem dúvida, a análise da construção discursiva e dos dispositivos de verdade analisada por Foucault adquire todo seu sentido ${ }^{2}$. Neste sentido, a bioética estaria atenta a que os saberes que predominam por diversas causas (dominação econômica, cultural, política, religiosa) não sejam os únicos que se estabeleçam como verdades absolutas em detrimento de qualquer outro saber existente chamado este, um saber sujeitado (assujetti).

Entende-se que o exemplo anterior não é uma prática condizente com a proposta original de Potter, pois, como elo entre ciências e humanidades a bioética não deveria assumir posições setoriais, ideologias, dogmas ou doutrinas, mas, definitivamente abarcar a pluralidade e a diversidade em seu mais amplo sentido, encontrando em todas elas um ponto em comum de convergência; nada mais que a própria definição de ética ${ }^{3}$. Aqui se encontra a diferença capital entre uma bioética neutra e uma bioética imparcial. A este respeito cabe dizer que desde seu início a bioética se inclina e se cimenta em valores específicos, resultando em que não seja neutra, mas, que busque uma imparcialidade, uma vez que a neutralidade refere-se a um estado de indiferença a qualquer influência de valores e princípios externos ou internos enquanto que a imparcialidade não nega estes princípios e valores, mas, ao mesmo tempo, não os utiliza para favorecer ou prejudicar

2. Para Foucault, o discurso é aquilo que permite que algo seja estabelecido como verdadeiro e que se insere na realidade através de um saber/poder, pois, não há saber sem uma prática discursiva definida. Através deste dispositivo (rede estabelecida entre diferentes elementos, como discurso e prática, por exemplo) os discursos estabelecem a divisão entre verdadeiro e falso, produzem objeto de conhecimento e os domínios do saber sobre estes objetos, tornando real o que inexiste, Michel Foucault, 1976.

3. A ética refere-se, portanto, a uma realidade humana que é construída histórica e socialmente a partir das relações coletivas dos seres humanos nas sociedades onde vivem; Adolfo Sánchez Vásquez,1997. 
qualquer parte envolvida em um determinado fenômeno. Em termos concretos isto significaria não privilegiar nem excluir qualquer valor da vida que estejam envolvidos em uma tomada de decisões (ética de vida). Assim, os princípios que sustentam a bioética seriam aqueles referentes à busca de um ponto em comum a partir de uma diversidade de expressões humanas. Encontramo-nos, portanto, com a edificação de portas ao redor da bioética, contudo, sem haver ainda esboçado suas pontes.

Nesta diferença entre neutralidade e imparcialidade é também onde encontramos a noção de laicidade como uma ferramenta de reflexão para concretizar a proposta bioética de Potter como uma ponte entre ciência e humanidades, tomando em consideração os princípios primeiros e fundamentais da relação entre valores e fatos biológicos. Se bem que este não é o espaço suficiente para resolver a questão da bioética como ponte entre ciências e humanidades, ao menos podemos propor, como objetivo deste artigo, a laicidade como uma ferramenta para resolver - em termos concretos - os problemas que mencionamos anteriormente e que dificultam o exercício da bioética tal e como foi proposta em suas raízes. Em outras palavras este não é o espaço para resolver o problema epistemológico da bioética como ponte entre ciências e humanidades, mas, de propor uma solução concreta ao problema fático da bioética como disciplina de conhecimento e sua aplicação direta no âmbito biomédico.

\section{Bioética e Laicidade}

Face às considerações anteriores cabe refletir sobre a laicidade como uma ferramenta que possui todas as condições de contribuir para o exercício ou aplicação de uma bioética que poderíamos chamar Arcaica (do grego Arché: primeiro e fundamental). Por sua vez, a laicidade corresponde a uma proposta política que busca fomentar o respeito e a equidade de tratamento para todos, não importando a origem étnica, a crença religiosa, a opção sexual, a posição ideológica, assim como visa garantir a liberdade de expressão, de culto e de consciência, em seu mais amplo sentido, sem imposições; este é o nó górdio da laicidade. Em suma, esta proposta busca não privilegiar aspectos particulares, nem tampouco excluir algum elemento particular (visão, valores, cultura, entre outros). E são estes princípios da laicidade ${ }^{4}$ que a impedem de ser neutra, uma vez que defende estes valores, e, ao mesmo tempo, a potencializa como uma ferramenta que sustenta a imparcialidade. $\mathrm{O}$ anterior nos permite pensar que a bioética enquanto

4. A declaração Universal da Laicidade no Século XXI aponta 3 princípios fundamentais, a saber: Respeito à liberdade de consciência e a sua prática individual e coletiva; Autonomia do civil (público) frente ao religioso (sagrado); e Ausência de discriminação direta ou indireta. 
disciplina - ao apoiar-se na laicidade como noção que incorpora uma série de princípios na prática política - poderia, em sua prática epistemológica, configurar-se em uma ponte concreta entre ciências e humanidades à medida que sem privilegiar nem excluir valores particulares logra exercer seus objetivos arcaicos. O anterior significa que a prática da bioética se viu emaranhada pela ausência de ferramentas políticas que resultem em práticas imparciais, portanto utilizáveis em qualquer situação, mas, pelo contrário, seja engessada em pugnas político-filosóficas infrutíferas e sem sentido que terminam por favorecer os valores predominantes. Outras reflexões semelhantes discorrem sobre a importância dos direitos humanos para um exercício imparcial das práticas em bioética (9). O mesmo sucede quando discutimos sobre os obstáculos que se encontram na geração de conhecimentos a partir de uma comunicação entre ciências e humanidades.

Esta consideração refletirá a abordagem humanista necessária, por exemplo, quando se examinam casos relativos a direitos sexuais e reprodutivos, conforme já descritos anteriormente no caso da medicalização da bioética aplicada a pessoas intersex (direitos sexuais e identidade) e, ainda, conforme detalharemos mais adiante revisando a questão da despenalização do aborto no Brasil (direitos reprodutivos). Todos estes são temas que nos descrevem claramente a necessária relação entre bioética (enquanto disciplina acadêmica) e laicidade (enquanto ferramenta de convivência), pois tem a ver com questões relativas às diferentes consciências, crenças, valores, entre outras características de todos os grupos humanos (nível de convivência) e suas formas de aplicá-las e decidilas (campo acadêmico).

A este respeito podemos exemplificar através dos casos comuns de objeção de consciência, cujo nó górdio que citamos anteriormente tem a ver com a maneira como não privilegiar nem excluir uma decisão pessoal (referida a um grupo moral) que exclui ou privilegia modos morais de vida de grupos particulares. Em outras palavras, como poder decidir sem que nossa consciência se veja constrangida e que nossa decisão não seja imposta ou constranja às decisões de consciência dos outros. É aqui onde apelamos à necessidade de uma relação estreita entre bioética e laicidade, independentemente do problema epistemológico que propõe a bioética como disciplina ponte entre as ciências e as humanidades. Como veremos esta relação nos permitirá aceitar - desde âmbitos institucionais da saúde pública - a objeção de consciência sem transgredir a liberdade de consciência de alhures.

Vários autores propuseram uma série de reflexões para estabelecer a laicidade como uma ferramenta de decisão pública e política. Para Roberto Blancarte a laicidade configura um regime social desenhado para garantir a liberdade de crenças e a liberdade de religião (10). O autor afirma que desde o ponto de vista histórico não existe nenhum lugar 
onde se pôde garantir a liberdade de religião que não tenha sido em um Estado laico, assim chamado ou não ${ }^{5}$. E, ainda, explica que o Estado laico possui uma série de características que se definem como tal, ou como Estado secular, e, somente neste contexto de Estado laico ou secular é que realmente se desenvolveu e se pôde garantir a liberdade de crenças, as liberdades civis em geral e as liberdades de religião em particular. Na mesma linha da definição anterior, Micheline Milot reitera que a laicidade evoca uma realidade política segundo a qual o Estado não tira sua legitimidade de uma Igreja ou de uma confissão religiosa, mas da soberania do povo (11). No entanto, é preciso compreender que a laicidade não é um evento único e acabado, mas em constante processo de conformação. De maneira geral, se trata de um processo passível inclusive de avanços e retrocessos. Neste sentido, outro importante estudioso da laicidade, Jean Baubérot, nos ensina que, a exceção das teocracias, não existe uma rigorosa separação de países em laicos ou não laicos, mas, existem países mais ou menos laicos, e, ainda, este mesmo país pode ser mais ou menos laico de acordo com os momentos de sua história e dos campos de aplicação da laicidade (12). Pensar a laicidade como ferramenta complementar à Bioética se traduz em pensar no respeito pela diversidade e sua aplicabilidade no que tange às distintas cosmovisões, sem imposição de nenhuma sobre outra. Em suma, as mais importantes reflexões atuais sobre a laicidade insistem em que não existe regime político possível que possa ser exitoso sem que exista uma autonomia das decisões políticas frente a qualquer âmbito religioso ou ideológico-filosófico chamado laico, secular ou qualquer outro (Blancarte) $^{6}$. Ou também, que qualquer decisão que incumba a coisa pública (respublica) necessita para sua legitimação a inclusão das decisões livres (se é que são possíveis em termos sociológicos) dos membros que conformam esse espaço público (Milot). Ou ainda mais, que esta autonomia do civil e do religioso, bem como a legitimação da soberania popular não são estáticas, mas necessitam uma constante contextualização geohistórica do mundo em que se vive (Baubérot). Os autores citados em alguma medida insistem em sua preocupação de incluir a diversidade cultural nas decisões coletivas, ou seja, que inclua, não privilegie e não discrimine a ninguém (nó górdio). Sendo assim, a laicidade, mais que uma ideologia ou um dogma é uma ferramenta possível para facilitar

5. Veja-se o caso de Inglaterra e Dinamarca que não somente não são Estados chamados laicos, sendo que cada um se define como Estados Confessionais (Cf. Cristianismo reformado), não obstante suas políticas públicas diferenciam entre decisões civis tratando de incluir todas as crenças e ideologias possíveis sem favorecer a nenhuma, inclusive a confissão do Estado.

6. Não é espaço aqui para fazer a distinção entre secular e laicidade, bastando dizer que o primeiro é um princípio de organização societal (diferenciação de esferas de convivência) e o segundo é um princípio de organização política (autonomia de poderes civis e religiosos). Conforme Gaytán Alcalá F, Fortes Rivas MC (coord) Democracia cristiana, cultura política y gobernanza. México, DF: Arkhé Ediciones, 2010. p.119-144. 
os intercâmbios entre os grupos e gerar uma con-vivência o mais harmoniosa possível. Sem dúvida, muitas reflexões e análises faltam por ser levadas a cabo para institucionalizar, formalizar e normalizar um diálogo entre culturas. Porém, para o problema que nos compete, a laicidade é uma ferramenta necessária, momentaneamente, desde o espaço público para fornecer os referentes necessários para uma possível normatividade institucional de convivência nos espaços públicos de interação, contudo, ainda assim não suficiente para a convivência da vida cotidiana em seu conjunto.

\section{Implicações da laicidade relativas ao âmbito da saúde pública}

Do ponto de vista prático, estas questões se refletem quando, por exemplo, discutimos temas polêmicos cujas definições são permeadas por crenças particulares, como a questão dos direitos sexuais e direitos reprodutivos já citada anteriormente. Pensar o aborto desde um referencial bioético implica necessariamente em ter como ponto central o não alinhamento com uma ou outra doutrina, filosofia ou crença em particular, mas de maneira que os pontos comuns sejam contemplados (ética) e as liberdades de consciência respeitadas (laicidade). Entretanto, percebe-se em distintas esferas a defesa de argumentações pessoais, disfarçadas de normativas éticas e sua consequente imposição aos outros. Aqui abordamos mais o tema das morais ou moralismo do que o tema da ética em si mesma. Portanto, pensar na questão dos direitos sexuais e direitos reprodutivos desde uma perspectiva laica em bioética permite a consideração pela diversidade e a não imposição, mas, muito antes pelo contrário, a possibilidade de escolha desde o referencial de liberdade de consciência de cada pessoa. Esta abordagem de uma bioética em consonância com a laicidade se aplica também a outros temas abarcados pela bioética, como questões de comunidades autóctones, distintas formas de discriminação, preferências religiosas, entre outras. Pensar nestes temas em consonância com a laicidade significa considerar a diversidade e tratar de estabelecer políticas públicas que contemplem esta diversidade, sem discriminação.

Contudo, vale lembrar que a existência de garantias constitucionais de um Estado laico ou secular, na prática não tem garantido o exercício da laicidade. No caso do Brasil, por exemplo, embora a separação Estado-Igreja exista desde o estabelecimento da República em 1889 e do decreto presidencial A-119 (13), a influência religiosa sobre decisões que afetam a toda a sociedade é notória. Como exemplo do anterior podemos citar a discussão sobre a despenalização do aborto no país. Com o objetivo de cumprir um dos pontos previstos no Plano Nacional de Políticas para as Mulheres, em 2005 o governo 
brasileiro constituiu uma Comissão Tripartite para a discussão sobre a descriminalização do aborto no país, composta por representantes dos Poderes Executivo e Legislativo, organizações da sociedade civil e do movimento de mulheres. No entanto, desde que o governo anunciou a intenção de discutir o tema, no início de 2005, representantes da sociedade, como segmentos da Igreja Católica e até mesmo o procurador-geral da República na época manifestaram-se contrários, conforme reportagem do jornal Folha de São Paulo em 08 de março de 2005, não por acaso Dia Internacional da Mulher (14). Causa surpresa a informação contida na reportagem de que na mesma semana seria definida qual a entidade religiosa acompanharia a discussão. A Secretaria de Políticas para as Mulheres propôs o Conselho Nacional de Igrejas Cristãs (CONIC) que reúne igrejas católicas, cristãs e evangélicas. Por sua vez, a CNBB (Conferência Nacional dos Bispos do Brasil) reclamou ao presidente Lula por ter se sentido excluída do debate. Contudo, a então ministra Nilcéa Freire, da Secretaria de Políticas para as Mulheres, afirmou que todos seriam ouvidos, mas que o Estado brasileiro é laico.

Este exemplo ilustra claramente o quanto a garantia constitucional não é o único balizador da laicidade, embora esta sofra influência direta do regime laico do Estado. Além disso, as próprias contradições existentes reiteram os avanços e retrocessos que permeiam este processo de laicização do Estado. Dois pontos chamam particularmente atenção quanto aos fatos reportados acima. O primeiro questionamento seria quanto à por qual razão as denominações religiosas deveriam acompanhar oficialmente a discussão. O outro diz respeito ao fato de pensar em denominações religiosas a partir de um recorte cristão, quando existem inúmeras outras denominações religiosas não cristãs, espiritualidades, filosofias, crenças e inclusive não crenças que configuram a pluralidade nacional com relação a questões espirituais. E, dentro desta perspectiva, um Estado laico visando contemplar a todas as crenças e não crenças, não deve privilegiar a nenhuma. Desde a perspectiva legislativa, esperava-se que manifestações e preferências pessoais não consistissem no carreador dominante das discussões sobre o Projeto de Lei (PL) n. 1.135 de 1991, sobre a descriminalização do aborto no país. Contudo, em 2008 o PL foi rejeitado tanto na Comissão de Seguridade Social e Família (CCSF) quanto na Comissão de Constituição e Justiça (CCJ) da Câmara dos Deputados (15). Embora tenham sido realizadas três audiências públicas no ano de 2007 visando escutar opiniões de especialistas para subsidiar a discussão do assunto, prevaleceram posicionamentos restritivos às liberdades de consciência, ou seja, à laicidade.

Seguindo a mesma linha do exposto anteriormente, em 2004 foi ajuizada ação pela Confederação Nacional dos Trabalhadores na Saúde (CNTS), visando à 
descriminalização da antecipação do parto em caso de gravidez de feto anencéfalo, com base na ofensa à dignidade humana da mãe, prevista no artigo $5^{\circ}$ da Constituição Federal. Mais uma vez, por se tratar de tema controverso, o mesmo foi objeto de audiências públicas realizadas em 2008 no Supremo Tribunal Federal e 2009 na Câmara dos Deputados, onde além da participação de representantes do governo e de especialistas da área da saúde e da sociedade civil também foram convidados representantes de algumas entidades religiosas, tais como Conferência Nacional dos Bispos do Brasil (CNBB), Católicas pelo Direito de Decidir (CDD), Igreja Universal, Federação Espírita Brasileira (FEB) e Conselho Nacional de Pastores do Brasil (CFPB) (16,17). Novamente se percebe que a intenção de escutar diversos segmentos da sociedade e entidades religiosas é genuína, contudo, discriminatória com relação à diversidade religiosa existente no país. Neste caso, o argumento de maioria não é aplicável, pois a diversidade se conjuga precisamente pela variabilidade e não pela quantidade.

Outro exemplo da influência da religião em assuntos públicos foi a repercussão da opinião dos candidatos à presidência da república nas últimas eleições de 2010 com relação à descriminalização do aborto. Algumas declarações dos candidatos mobilizaram a sociedade de maneira desmedida. É inadmissível que em um país onde existe formalmente a separação Estado-Igreja uma questão de saúde pública como a descriminalização do aborto seja pautada por posicionamentos religiosos ou preferências pessoais de dirigentes ou futuros dirigentes. Ainda mais grave é o fato da repercussão deste assunto poder influenciar na escolha dos candidatos por parte dos cidadãos, ainda que seja uma minoria deles.

Com base nos fatos acima descritos, percebe-se claramente que as políticas públicas seguem sendo discutidas e, em certas ocasiões até mesmo estabelecidas, sem considerar a diversidade em termos de liberdade de consciência; e, ainda, algumas vezes privilegiando visões majoritárias. Neste sentido, a discussão e o enfrentamento de temas polêmicos ou conflituosos, tais como os citados anteriormente, que envolvem direitos sexuais e reprodutivos e que, portanto envolvem a ética da vida (bioética), muito se beneficiaria se assumisse a imparcialidade necessária para incluir a todas as liberdades de consciência, crenças e não crenças, sem imposição de nenhuma sobre outra (laicidade). Desde uma perspectiva prática, a despenalização do aborto, por exemplo, se sustenta a partir do princípio de a decisão de realizar ou não um aborto é uma decisão pessoal, de acordo com a consciência de cada indivíduo, e, esta liberdade de consciência de cada um deve ser respeitada. Ao discutir a despenalização do aborto dando voz a opiniões de apenas alguns setores da sociedade se está privilegiando esta visão de apenas alguns 
grupos, geralmente dominantes, e ainda, favorecendo a imposição de visões particulares sobre a totalidade dos membros de uma sociedade que por si é diversa, conforme discutido anteriormente neste artigo. Não existe justificativa para a imposição de uma determinada crença ou não crença ao outro. Portanto, sendo o aborto um dos temas mais debatidos no campo da bioética, entende-se ser urgente a incorporação da laicidade enquanto ferramenta fundamental a esta discussão.

Buscando resgatar a bioética enquanto ponte entre ciências e humanidades podemos considerar a laicidade como importante ferramenta capaz de auxiliar na reconstrução desta ponte, uma vez que a laicidade pode aportar humanismo à bioética, pois necessariamente evoca conteúdos socio-político-culturais, que se referem a direitos fundamentais de todos os seres humanos, além de que também se baseia em princípios ou valores. Ou seja, a abordagem dos conflitos aos quais a bioética se ocupa desde uma perspectiva em conexão com a laicidade permite levar a cabo uma bioética imparcial, não necessariamente neutra, uma vez que defende valores, mas, uma bioética que permita a reflexão e a tomada de decisões sobre questões envolvendo a ética da vida de maneira a contemplar a diversidade de crenças, não crenças, opções sexuais, ideológicas, entre outras liberdades de consciência. E, sobretudo, a laicidade, ao defender a não imposição de crenças ou não crenças aos outros, evoca a promoção do diálogo e da negociação de espaços e decisões que contemplem além dos fatos biológicos, a diversidade social, política, econômica, cultural, religiosa, espiritual entre outras, favorecendo a construção de uma verdadeira ponte entre ciências e humanidades.

\section{Referências}

1. Potter, VR. Bioethics: bridge to the future. New Jersey: Prentice Hall; 1971.

2. Jahr F. Bio=Ethik. Eine Umschau über die ethichen Beziehung des Menschen zu Tier und Pflanze. Kosmos 1927; 24:2-4.

3. Dilthey W. Teoria de la concepción del mundo. México: FCE; 1954.

4. González-Valenzuela J. ¿Que ética para la bioética? In: González-Valenzuela J, coordinadora. Perspectivas de bioética. México: Fondo de Cultura Econômica; 2008. p.950 .

5. Weber PR. Ciência y técnica: ¿hacia un nuevo humanismo bioético? In: El desafío de la bioética. Río AA, Weber PR, coordinadoras. México D.F.: Fondo de Cultura Econômica; 2009. p. 15-28.

6. Clotet J. A bioética: uma ética aplicada em destaque. In: Caponi GA, Leopardi MT, Caponi SNC. A saúde como desafio ético. Florianópolis: Anais do I Seminário Internacional de Filosofia e Saúde; 1994. p.115-129. 
7. Fortes PAC, Zoboli ELCP. Bioética e Saúde Pública: entre o individual e o coletivo. In: Fortes PAC, Zoboli ELCP, organizadores. Bioética e saúde pública. 2 ed. São Paulo: Loyola, Centro Universitário São Camilo; 2004. p.11-24.

8. Sádaba J. Principios de Bioética Laica. Barcelona: Gedisa; 2004. p.37-47.

9. Tealdi JC. Bioética de los derechos humanos. Investigaciones biomédicas y dignidad humana. México DF: UNAM; 2008.

10. Blancarte R. Laicidad y Bioética. In: Aspectos sociales de la bioética. Soberón G, Feinholz D, compiladores. México D. F.: Comisión Nacional de Bioética; 2009. p.53-70. 11. Milot M. La laïcité. Otawa: Novalis; 2008.

12. Baubérot J. Historia de la laicidad francesa. México: Zinacantepec; 2005.

13. Corrêa da Costa ME. Apontamentos sobre a liberdade religiosa e a formação do Estado Laico. In: Lorea RA, organizador. Em defesa das Liberdades Laicas. Porto Alegre: Livraria do Advogado Editora; 2008. p.97-116.

14. Lage J. Grupo começa a discutir descriminalização do aborto neste mês. Folha OnLine. 2005 Mar 8; Cotidiano. [citado em 2010 jul. 2010]. Disponível em: http://www1.folha. uol.com.br/folha/cotidiano/ult95u106512.shtml.

15. Câmara dos Deputados [Internet]. Brasília (DF): Projetos de lei e outras proposições. c1997 - [citado em 2010 fev. 02]. Disponível em: http://www.camara.gov.br/sileg/ Prop_Detalhe.asp?id=16299.

16. STF retoma audiência pública sobre fetos anencéfalos - Tribunal deverá decidir se autoriza a interrupção desse tipo de gravidez ainda neste ano. Estadão.com.br. 2008 Mar 27; Saúde. [citado em 2010 dez. 02]. Disponível em: http://www.estadao.com.br/ noticias/vidae,,231870,0.htm.

17. Observatório Brasil da Igualdade de Gênero [Internet]. Brasília (DF): Secretaria de Políticas para as Mulheres da Presidência da República. c2009 - [citado em 2010 dez. 02]. Aborto de fetos anencéfalos é discutido em Audiência Pública na Câmara dos Deputados. Disponível em: http://www.observatoriodegenero.gov.br/menu/noticias/aborto-defetos-anencefalos-e-discutido-em-audiencia-publica-na-camara-dos-deputados. 